\title{
EVALUASI PERTUMBUHAN KATAK BENGGALA (Rana catesbeiana Shaw) HASIL PEMIJAHAN DARI STOK BALI, KLATEN, DAN SLEMAN
}

\author{
Honorius Mundriyanto*), Lies Emmawati Hadie**), dan Wartono Hadie ${ }^{* *}$
}

\begin{abstract}
ABSTRAK
Evaluasi karakter pertumbuhan katak benggala stok Bali, Klaten, dan Sleman dilakukan untuk mencari kandidat populasi dasar. Pemijahan induk-induk katak benggala dilaksanakan secara fullsibs dari masing-masing stok dan percil yang diperoleh dipelihara selama 22 minggu. Pemeliharaan percil menggunakan bak beton berukuran $1 \times 1 \times 1 \mathrm{~m}^{3}$ dengan kepadatan 75 ekor/ bak. Pakan berupa pelet terapung diberikan sebanyak $1,5 \%-3 \%$ per hari. Hasil pengamatan selama 22 minggu menunjukkan bahwa katak benggala stok Sleman merupakan kandidat untuk dimanfaatkan sebagai populasi dasar. Karakter fenotip spesifik katak benggala stok Sleman memiliki pertumbuhan bobot yang lebih cepat dibanding turunan Bali dan Klaten $(P<0,05)$. Model populasi dalam karakter bobot relatif homogen, hal ini akan berdampak positif dalam menghasilkan individu katak benggala yang relatif seragam.
\end{abstract}

\begin{abstract}
Growth evaluation of bullfrog (Rana catesbeiana Shaw) spawns from Bali, Klaten, and Sleman broodstock. By: Honorius Mundriyanto, Lies Emmawati Hadie, and Wartono Hadie
\end{abstract}

Growth character of bullfrog spawns from Bali, Klaten, and Sleman were evaluated in order to select basic population candidate. Bullfrog of broodstocks was spawned by full sibs method on each stock was reared for 22 weeks. Concrete tank were used for rearing with $1 \times 1 \times 1 \mathrm{~m}^{3}$ in size and density was 75 individual/tank. Floating pellet was used for rearing period, and feeding rate is $1.5 \%-3.0 \% /$ day. The result showed that bullfrog broodstock of Sleman had change as candidate of basic population. Specific character off spring of Sleman is having faster growth than Bali and Klaten. Population model in weight character is relatively homogenous, thus had advantage impact on bullfrog individually.

\section{KEYWORDS: bullfrog, growth, broodstock, population, rearing}

\section{PENDAHULUAN}

Masalah yang dihadapi peternak katak benggala (Rana catesbeiana Shaw) saat ini adalah terjadinya penurunan pertumbuhan (Suhartono, 1999). Penurunan pertumbuhan tersebut diduga kuat karena terjadinya penurunan mutu genetik secara fenotip maupun genotip. Hal itu disebabkan peternak katak kurang memahami dalam mengelola induk katak secara benar. Akibat lanjut kelemahan dalam pengelolaan induk dapat menyebabkan terjadinya silang dalam (inbreeding) yang tidak terarah.

Menurut Kirpichnikov (1981), salah satu karakter penting dalam budi daya adalah per- tumbuhan. Oleh karena itu, karakter tersebut perlu diseleksi agar dapat diperoleh katak benggala yang memiliki pertumbuhan yang relatif cepat. Dalam upaya meningkatkan mutu genetik katak lembu, dapat ditempuh dengan menerapkan program pemuliaan. Salah satu metode yang dapat diaplikasikan adalah melalui seleksi (Tave, 1986; Hardjamulia, 1988). Metode seleksi bertujuan untuk mendapatkan induk unggul dengan harapan terjadinya peningkatan keragaman pada generasi berikutnya yang bersifat permanen. Penentuan strategi dalam pemuliaan ditentukan berdasarkan nilai pewarisan dalam suatu karakter tertentu. Pada umumnya nilai pewarisan ini dikenal sebagai heritabilitas

\footnotetext{
*) Loka Riset Budidaya Ikan Hias Air Tawar, Depok (Alm.)

**) Peneliti pada Pusat Riset Perikanan Budidaya, Jakarta
} 
yang nilai maksimumnya adalah 1,0. Kriteria dalam heritabilitas terbagi dalam tiga kategori yaitu kategori rendah jika heritabilitas suatu karakter nilainya berkisar antara 0,0-0,2; kategori sedang $>0,2-0,3$; dan kategori tinggi $>0,3$ (Falconer, 1986).

Berdasarkan hasil penelitian, nilai heritabilitas katak benggala pada karakter bobot mencapai 0,85 pada stok Bali dan 0,41 pada stok Klaten, serta stok Sleman meraih nilai 0,09 pada tingkatan umur 8 minggu (Mundriyanto et al., 2001). Nilai heritabilitas yang tinggi dalam karakter pertumbuhan ini akan mendukung keberhasilan seleksi dan akan berdampak terhadap peningkatan pertumbuhan katak benggala (Malecha et al. dalam Hadie et al., 1998).

Penelitian ini dilakukan untuk mengevaluasi sifat pertumbuhan populasi katak benggala dari stok Bali, Klaten, dan Sleman agar populasi dasar yang dibentuk dapat dimanfaatkan dalam meningkatkan pertumbuhan katak benggala.

\section{BAHAN DAN METODE}

Penelitian dilaksanakan di Loka Riset Budidaya Ikan Hias Air Tawar, Depok pada tahun 2004. Katak benggala yang digunakan adalah stok Bali, Klaten, dan Sleman yang berasal dari introduksi. Setiap populasi diwakili oleh dua famili dari stok Bali, tiga famili dari stok Klaten dan dua famili dari stok Sleman. Pemijahan katak dilakukan dalam kandang yang dilakukan secara fullsibs yakni satu jantan dikawinkan dengan satu induk betina. Percil yang dihasilkan dari ketiga stok tersebut kemudian dipelihara di dalam bak beton. Bak yang digunakan berukuran $1 \times 1 \times 1 \mathrm{~m}^{3}$ dan kepadatan percil adalah 75 ekor/ $\mathrm{m}^{2}$. Pemeliharaan percil berlangsung selama 22 minggu hingga mencapai ukuran konsumsi. Pakan yang digunakan berupa pelet terapung komersial dengan diameter $2-6 \mathrm{~mm}$. Jumlah pakan yang diberikan sebanyak $1,5 \%-3,0 \%$ per hari bobot biomassa, dengan frekuensi pemberian dua kali sehari yaitu pada pukul 08.00 dan 12.00. Penggantian air dilakukan setiap pagi dengan cara mengganti air secara total.

Karakter morfologi populasi katak benggala yang diamati meliputi bobot rata- rata, bobot maksimum, bobot minimum, panjang standar, panjang total. Setiap karakter tersebut dihitung nilai standar deviasi, kurtosis, serta skewness. Pengamatan karakter morfologi turunan katak benggala meliputi laju pertumbuhah harian $(\%$ hari), pertambahan bobot mutlak (gram), dan sintasan (\%). Panjang standar kodok diukur dari ujung mulut sampai anus, sedangkan panjang total diukur dari ujung mulut sampai ujung kaki belakang yang diluruskan. Parameter penunjang yang diamati adalah suhu dan kelembaban udara yang dilakukan setiap hari dengan alat higrometer. Sampling dilakukan setiap 2 minggu sekali.

Rancangan penelitian yang digunakan adalah Rancangan Acak Lengkap dan setiap perlakuan tersebut diulang tiga kali.

Laju pertumbuhan harian dihitung berdasarkan rumus:

$$
\alpha=\sqrt[t]{\frac{W_{t}}{W_{o}}}-1 \times 100 \%
$$

$\mathrm{W}_{\mathrm{t}}=$ bobot katak pada hari ke- $\mathrm{t}$

$\mathrm{W}_{\mathrm{o}}=$ bobot katak pada awal penelitian

$\alpha=$ laju pertumbuhan

(Huisman, 1976)

Sintasan dihitung berdasarkan rumus:

$$
\mathrm{S}=\mathrm{N}_{\mathrm{t}} / \mathrm{N}_{\mathrm{o}} \times 100 \%
$$

$\mathrm{N}_{\mathrm{t}}=$ jumlah ikan pada akhir penelitian (ekor)

$\mathrm{N}_{\mathrm{o}}=$ jumlah ikan pada awal penelitian (ekor)

$\mathrm{S}=\operatorname{sintasan}(\%)$

Analisis data menggunakan sidik ragam untuk memperhitungkan pengaruh perlakuan terhadap hewan uji.

\section{HASIL DAN BAHASAN}

Karakter morfologi dan produktivitas katak benggala dari stok Bali, Klaten, dan Sleman dapat dilihat pada Tabel 1 .

Karakter morfologi katak benggala stok Sleman memperlihatkan nilai yang lebih tinggi dalam mencapai bobot rata- rata dan bobot maksimum dibandingkan dengan stok dari Bali dan Klaten (Tabel 1). Dalam karakter bobot katak dari stok Klaten menduduki ranking kedua dan stok dari Bali menempati urutan yang terakhir. Jika dikaitkan dengan karakter yang bernilai ekonomi, maka yang menjadi tolok ukur adalah bobot badan dan bukan ukuran panjang badan. Hal ini merupakan indikasi bahwa stok Sleman memiliki sifat genetis yang potensial untuk dikembangkan. Nilai skewness mencapai 0,3 dan nilai kurtosis 0,02 ; hal ini berarti bahwa kemiringan model populasinya relatif kecil. Sehingga dapat dinyatakan bahwa katak stok Sleman merupa- 
Tabel 1. Karakter morfologi dan produktivitas katak benggala stok Bali, Klaten, dan Sleman pada umur 22 minggu yang meliputi: bobot rata- rata \pm SD, bobot maksimum (gram), bobot minimum (gram), skewness, dan kurtosis, laju pertumbuhan harian (\% hari), pertambahan bobot mutlak (gram), dan sintasan (\%)

Table 1. Morphological character and productivity of bull frog stock from Bali, Klaten, and Sleman on 22 weeks of age, include: average weight \pm SD, maximum weight (gram), minimum weight (gram), skewness, kurtosis, daily growth rate (\%/day), absolute weight gain (gram), and survival rate (\%)

\begin{tabular}{|c|c|c|c|}
\hline $\begin{array}{l}\text { Parameter } \\
\text { Parameter }\end{array}$ & $\begin{array}{l}\text { Stok Bali } \\
\text { Bali stock }\end{array}$ & $\begin{array}{l}\text { Stok Klaten } \\
\text { Klaten stock }\end{array}$ & $\begin{array}{l}\text { Stok Sleman } \\
\text { Sleman stock }\end{array}$ \\
\hline Bobot rata \pm SD & $205.23 \pm 68.98$ & $229.73 \pm 58.52$ & $237.25 \pm 66.2$ \\
\hline \multicolumn{4}{|l|}{ Average weight $\pm S D$} \\
\hline Bobot maksimum & 388.5 & 355 & 401.5 \\
\hline \multicolumn{4}{|l|}{ Maximum weight } \\
\hline Bobot minimum & 75 & 78 & 72 \\
\hline \multicolumn{4}{|l|}{ Minimum weight } \\
\hline Kemiringan & 0.07 & 0.31 & 0.3 \\
\hline \multicolumn{4}{|l|}{ Skewness } \\
\hline Koefisien kurtosis & 0.49 & 0.55 & 0.02 \\
\hline \multicolumn{4}{|l|}{ Kurtosis coeffisien } \\
\hline Laju pertumbuhan harian & 1.83 & 1.81 & 1.92 \\
\hline \multicolumn{4}{|l|}{ Daily growth rate } \\
\hline Pertambahan bobot mutlak & $210.32^{a}$ & $220.47^{a}$ & $240.98^{b}$ \\
\hline \multicolumn{4}{|l|}{ Absolute weight gain } \\
\hline Sintasan & $62.0^{a}$ & $63.11^{\mathrm{a}}$ & $53.33^{a}$ \\
\hline Survival rate & & & \\
\hline
\end{tabular}

* Angka yang diikuti huruf (notasi) yang sama pada kolom menunjukkan tidak terdapat perbedaan yang nyata $(P>0,05)$

* The values followed by similar superscript in the same column were not significantly different $(P>0.05)$

kan populasi dengan model cenderung homogen dalam karakter bobot.

Berdasarkan ANOVA pertambahan bobot mutlak di antara ketiga genotip menunjukkan perbedaan pertumbuhan yang secara statistik berbeda nyata $(P<0,05)$. Stok Sleman memperlihatkan pertumbuhan yang terbaik dibandingkan dengan stok Klaten dan Bali. Dengan demikian katak benggala stok Sleman dapat dijadikan kandidat sebagai populasi dasar yang mempunyai karakter spesifik yaitu cepat dalam pertumbuhan bobotnya. Sintasan yang dicapai oleh katak stok Klaten dan Bali lebih tinggi dibandingkan dengan Sleman yaitu sebesar $9,8 \%$ dan $8,7 \%$ Namun berdasarkan analisis keragaman maka perbedaan tersebut tidak menunjukkan perbedaan yang nyata secara statistik ( $P>0,05)$. Fakta ini memperkuat justifikasi untuk menetapkan katak stok Sleman sebagai populasi dasar yang akan memberikan dampak positif dalam pengembangan pemuliaan katak. Selain itu, model populasi katak stok Sleman menunjukkan karakter yang cenderung homogen dalam pertumbuhan bobot. Hal ini juga merupakan aspek positif yang akan mendukung keberhasilan dalam pengembangan katak benggala.

Faktor lingkungan merupakan salah satu penentu dalam mendukung pertumbuhan katak benggala, seperti kelembaban udara dan suhu. Kelembaban udara selama penelitian berkisar antara $41,0 \%-93,0 \%$ dan suhu udara berkisar antara $23,0^{\circ} \mathrm{C}-34,0^{\circ} \mathrm{C}$. Data ini menunjukkan bahwa kondisi lingkungan cukup baik untuk mendukung pertumbuhan katak benggala. Suhu harian katak benggala untuk aktivitas normal berkisar antara $26,0^{\circ} \mathrm{C}-33^{\circ} \mathrm{C}$ (Lillywhite, 1970). Pada suhu $26,0^{\circ} \mathrm{C}-30,0^{\circ} \mathrm{C}$ 
katak cenderung aktif dan jarang beristirahat, sebaliknya pada suhu $31,0^{\circ} \mathrm{C}-33,0^{\circ} \mathrm{C}$ katak akan mengalami ketidaknyamanan, sedangkan pada suhu $34,0^{\circ} \mathrm{C}-36,0^{\circ} \mathrm{C}$ katak akan meIoncat- Ioncat tanpa tujuan dan pada suhu $37,0^{\circ} \mathrm{C}-39,0^{\circ} \mathrm{C}$ katak akan mati.

\section{KESIMPULAN}

Karakter spesifik katak benggala stok Sleman yaitu memiliki pertumbuhan bobot $240,98 \mathrm{~g}$, lebih cepat dibanding stok Bali dan Klaten. Model populasi dalam karakter bobot relatif homogen, sehingga akan didapatkan individu katak benggala yang relatif seragam. Dalam pengembangan pemuliaan katak benggala, genotipa Sleman merupakan kandidat untuk dimanfaatkan sebagai salah satu komponen dalam pembentukan populasi dasar katak benggala.

\section{DAFTAR PUSTAKA}

Falconer, D.S. 1986. Introduction to Quantitative Genetics. Longman Group Ltd. England. p.160-180.

Hadie, L.E., Jaelani, I.I. Kusmini, dan Sudarto. 1998. Implementasi indeks seleksi dalam Upaya peningkatn pertumbuhan udang galah (M. rosenbergii). J. Pen. Per. Indonesia. 4(1): 47-54.

Hadie, W., H. Mundriyanto, Rusmaedi, dan L.E. Hadie. 2000. Truss morphometric katak benggala Rana catesbeiana Shaw untuk mendukung program pemuliaan berkeIanjutan. J. Pen. Sains dan Teknologi. 6(3): 43-53.
Hardjamulia, A. 1988. Penyediaan Induk untuk Usaha Pembenihan Ikan Budidaya Air Tawar. Universitas Padjadjaran dengan Balitbang Pertanian- Departemen Pertanian. $26 \mathrm{pp}$.

Huisman, F.A. 1976. Food conversion efficiences at maintenance and production feed for carp (Cyprinus carpio L) and rainbow trout (Salmonella gaindneri). Aquaculture. 9: $259 \mathrm{pp}$.

Kirpichnikov, V.S. 1981. Genetic Bases of Fish Selection. Springer Verlag. Berlin Heidelberg, New York. 107 pp.

Lillywhite, H. 1970. Behavioral Temperature Regulation in the Bullfrog (R. catesbeiana Shaw). Copeia 1. p.158-168.

Mundriyanto, H., L.E. Hadie, W. Hadie, dan T. Kadarini. 2001. Evaluasi heritabilitas Trait pertumbuhan kodok lembu untuk membentuk populasi dasar. Makalah disampaikan dalam Seminar Hasil Penelitian Perikanan Air Tawar, tanggal 12 Maret 2001 di Balitkanwar Sukamandi. 7 pp.

Suhartono, G. 1999. Budidaya katak lembu atau bullfrog ( $R$. catesbeiana Shaw). Makalah Disampaikan pada temu Informasi Sub Sektor Perikanan tanggal 22-23 Maret 2001 di IPPTP Wonocolo Surabaya. Petani kodok di Pacet, Mojokerto, Jawa Timur.13 $\mathrm{pp}$.

Tave, D. 1986. Genetics for Fish Hatchery Managers. AVI. Publishing Co.Inc. Westport Connecticut. p. 122-145. 